\title{
REFUGIADOS AMBIENTAIS NO CONTEXTO DO AQUECIMENTO GLOBAL: UMA ANÁLISE DO CASO IOANE TEITIOTA E A PROTEÇÃO INTERNACIONAL DOS DIREITOS HUMANOS
}

\author{
Deilton Ribeiro Brasil* \\ Rayssa Rodrigues Lopes**
}

\begin{tabular}{l|l}
\hline RECEBIDO EM: & 17.10 .2020 \\
\hline APROVADO EM: & 30.3 .2021 \\
\hline
\end{tabular}

* Pós-doutor em Direito pela Università degli Studi di Messina, Itália. Doutor em Direito pela Universidade Gama Filho (UGF-RJ). Professor da Graduação e do PPGD. Mestrado e doutorado em Proteção dos Direitos Fundamentais da Universidade de Itaúna (UIT); Faculdades Santo Agostinho (FASASETE-AFYA); Faculdade de Direito de Conselheiro Lafaiete (FDCL). Professor visitante do PPGD da Universidade de Caxias do Sul (UCS). E-mail: deilton. ribeiro@terra.com.br

** Mestranda no Programa de Pós-Graduação Stricto Sensu em Proteção dos Direitos Fundamentais da Universidade de Itaúna/MG. Especialista em Direito do Consumidor (Faculdade Damásio/Ibmec). Bacharel em Direito pela Universidade de Itaúna. http://lattes.cnpq.br/8771613963709490.E-mail: rayssarl@yahoo.com.br 
- RESUMO: O presente trabalho tem como objetivo analisar a proteção internacional dos refugiados ambientais, categoria de migrantes assim denominados por se deslocarem em razão das situações de risco e vulnerabilidade em que se encontravam no seu lugar de origem, motivados pelas mudanças climáticas. Atenta-se notadamente ao caso de Ioane Teitiota, habitante do Kiribati que teve o status de refugiado ambiental negado pela Alta Corte de Justiça da Nova Zelândia, o qual foi posteriormente reconhecido pela Organização das Nações Unidas, e faz-se um exame aprofundado dos motivos para a recusa e da necessidade de segurança jurídica internacional e garantia dos direitos humanos. Com a discussão sobre o regime jurídico aplicável às pessoas que recorrem à migração, fica constatada a dificuldade para a criação de um instrumento normativo específico para os refugiados ambientais motivados pelo aquecimento global. Para tanto, utilizou-se o método de pesquisa dedutivo-hipotético, por meio da exposição de posicionamentos doutrinários e jurisprudenciais.

PALAVRAS-CHAVE: Direito internacional; refugiados ambientais; refugiados climáticos; mudanças climáticas; aquecimento global.

\section{ENVIRONMENTAL REFUGEES IN THE CONTEXT OF GLOBAL WARMING: AN ANALYSIS OF THE IOANE TEITIOTA CASE AND THE INTERNATIONAL PROTECTION OF HUMAN RIGHTS}

- ABSTRACт: The objective of this work is to analyze the international protection of environmental refugees: a category of migrants named because of their move because of the risk and vulnerability situations in which they found themselves in their place of origin, motivated by climate change. Particular attention is due to the case of loane Teitiota, an inhabitant of Kiribati who denied environmental refugee status by the New Zealand High Court of Justice, which later recognized by the United Nations, and a thorough examination of the reasons is made for the refusal and the need for international legal security and guarantee of human rights. With the discussion on the legal regime applicable to people who resort to migration, the difficulty in creating a specific regulatory instrument for environmental refugees motivated by the global warming evidenced. For that, the 
deductive-hypothetical research method used, through the exposition of doctrinal and jurisprudential positions.

neywords: International law; environmental refugees; climate refugees; climate changes; global warming.

\section{Introdução}

Por abordar um assunto de repercussão no contexto nacional e internacional, a presente pesquisa se justifica diante do crescente número de refugiados ambientais que se encontram nessa condição, principalmente, pelos impactos relacionados às alterações climáticas, necessitando, assim, de proteção internacional e humanitária.

É fundamental observar que o Direito Internacional possui considerável relevância entre os ramos do Direito, haja vista a conservação de valores fundamentais para garantir os direitos humanos, em observância do princípio pro homine.

Ademais, as dificuldades em torno do consenso sobre uma definição jurídica e a natureza do regime de proteção dos refugiados, possuem como fundamento as normas vigentes do Direito Internacional, do Direito Internacional Humanitário e do Direito Internacional do Meio Ambiente, o que expõe as limitações do Direito Internacional Público atual para conferir tratamento adequado à complexidade do problema em questão.

Assim, o estudo objetiva estimular o debate acerca da dimensão humana e da progressão histórica das incertezas e inseguranças geradas pelas transformações ambientais e climáticas agravadas pela produção industrial, além de reflexões sobre as consequências das migrações motivadas por fatores ambientais, e da conceituação do instituto dos refugiados, inicialmente reconhecido na Convenção Relativa ao Estatuto dos Refugiados de 1951, a partir do qual se fez possível abordar os mecanismos de proteção internacional dos deslocados ambientais.

Há, inicialmente, uma síntese das características das mudanças climáticas causadas pelo aquecimento global e os desastres ambientais gerados, defronte a globalização e produção industrial acelerada, sucedendo o exame dos riscos e da vulnerabilidade assumidos pelos sujeitos que habitam as áreas afetadas.

Posteriormente, é estabelecida uma abordagem de proteção internacional dos migrantes e necessidade de se distinguir os migrantes dos refugiados para prosseguir no estudo e se aprofundar no reconhecimento de mecanismos competentes de proteção e 
integração de pessoas refugiadas, para, então, elucidar-se sobre o nascimento e os debates sobre a categoria dos refugiados ambientais e seu reconhecimento pelo Direito Internacional.

Por último, disserta-se sobre o Kiribati e as regiões insulares do Pacífico mais afetadas pelo aquecimento global, e descreve-se o caso específico eleito para exemplificar a dificuldade em se tutelar os direitos dos refugiados ambientais: Ioane Teitiota do arquipélago do Kiribati versus Nova Zelândia e os motivos da decisão negativa, mesmo constatando-se que o país sofre com diversos problemas climáticos.

Por fim, diante da emergência do reconhecimento de uma categoria específica de pessoas na ordem internacional e da ausência de proteção jurídica pelos instrumentos internacionais vigentes, a pesquisa se completa com uma ponderação para a demanda, buscando um consenso sobre a aplicabilidade mais razoável da norma predominante em cada caso concreto.

O método utilizado para a realização do trabalho foi o dedutivo-hipotético com a abordagem de categorias consideradas fundamentais para o desenvolvimento do tema. Os procedimentos técnicos utilizados na pesquisa para coleta de dados foram essencialmente a pesquisa bibliográfica.

O levantamento bibliográfico forneceu as bases teóricas e doutrinárias a partir de livros e textos de autores de referência, tanto nacionais como estrangeiros. Enquanto o enquadramento bibliográfico utiliza-se da fundamentação dos autores sobre um assunto, o documental articula materiais que não receberam ainda o devido tratamento analítico. A fonte primeira da pesquisa é a bibliográfica que instruiu a análise da legislação constitucional e a infraconstitucional, bem como a doutrina que informa os conceitos de ordem dogmática.

\section{Desastres ambientais, mudanças climáticas e aquecimento global: definição e ascensão}

O mundo vive um modelo capitalista globalizado no momento, que busca cada vez mais o desenvolvimento econômico e tecnológico. E para abastecer o consumo, é imprescindível produzir mais e, consequentemente, é necessário mais espaço, além da gradativa geração de resíduos. Conforme tratado por Saliba e Ribeiro (2019, p. 74), o crescimento da produção tem aumentado a geração de gases que alteram a dinâmica do efeito estufa, e mesmo com a existência de Declarações Internacionais e acordos vigentes sobre 
a redução contínua das emissões desses gases, vários países não se mostram adeptos a assumirem compromissos com a restrição.

As mudanças climáticas resultam do aquecimento global. Com o degelo das calotas polares, o aumento do nível do mar, incêndios florestais e secas prolongadas, diversos locais se tornarão inabitáveis ao longo do tempo. Os recursos naturais limitados, como água potável, tendem a se tornar cada vez mais escassos em muitas partes do mundo. As plantações e o gado lutam para sobreviver diante das mudanças climáticas, se tornam muito quentes e secas, ou muito frias e úmidas, ameaçando os meios de subsistência e agravando a insegurança alimentar. Os impactos das mudanças climáticas são imensos e, com isso, se faz necessária a adaptação humana diante das mudanças ambientais, vemos casos nos quais as pessoas são forçadas a deslocarem-se de suas casas, de seus países, pelos efeitos das mudanças climáticas e dos desastres ambientais.

Após 1850, com a Era Industrial, as primeiras alterações climáticas como resultado da ação humana são percebidas. A partir de então, no intuito de propor ações preventivas e futuras, alguns compromissos internacionais foram firmados entre os Estados, como exemplo, os apontados por Noschang e Bica (2018, p. 137): Convenção de Genebra (1979) sobre "Poluições Atmosféricas Transfronteiriças de Longa Distância”, a Convenção de Viena (1985) sobre "Proteção da Camada de Ozônio", Protocolo de Montreal (1987) sobre "Substâncias que Destroem a Camada de Ozônio", Convenção-Quadro das Nações Unidas sobre Mudanças Climáticas de 1992, Protocolo de Quioto de 1997 e Acordo de Paris de 2016.

As mudanças climáticas acarretam mudanças humanas quando determinam o deslocamento de seres humanos. Temporadas de seca prolongada ou períodos de chuva prolongada geram escassez hídrica e as cheias dos rios em determinados locais, respectivamente, o que leva a população a migrar em busca de água potável e alimentos. Migrações motivadas por fatores ambientais são frequentemente registradas na história, entretanto, os problemas ambientais enfrentados atualmente destacam-se por indução ou aceleração devido ao padrão internacional de consumo e pela produção industrial, gerando um novo debate para o direito internacional: a migração de pessoas de seu lugar de origem em razão de problemas ambientais agravados pelas mudanças climáticas.

Segundo o relatório Groundswell do Banco Mundial, até 2050, mais de 143 milhões de pessoas na África Subsaariana, América Latina e Sul da Ásia poderiam ser forçadas a deixar suas casas e se deslocar em busca de lugares menos vulneráveis para morar (BANCO MUNDIAL, 2018, p. 28). 
A vulnerabilidade e o risco são condições que possibilitam a identificação da interferência na relação do homem com o meio ambiente, causada pelas alterações ambientais (BRASIL; COSTA, 2018, p. 169). As problemáticas baseiam-se nos desafios que permeiam o tema desigualdade ambiental e a proteção dos direitos humanos. A progressiva degradação de recursos ambientais essenciais compromete a vida e a segurança de indivíduos, grupos e comunidades inteiras em todo o mundo, a ponto de inviabilizar a sobrevivência em seus locais de origem, provocando novas situações jurídicas que precisam ser reguladas pelo Direito Internacional.

De acordo com Lycia Brasil, pesquisadora do Instituto Igarapé em entrevista para o Jornal da Band, atualmente, mais de 2 milhões de pessoas foram forçadas a se deslocarem devido a desastres, e as comunidades com menores rendas são as mais expostas a esses impactos, tendo em vista sua dependência do ecossistema local e a sua atividade econômica, majoritariamente movida pela agricultura (BAND, 2020, on-line). Os principais motivos são degelos, enchentes, furacões, incêndios e secas.

\section{A proteção internacional dos migrantes: distinção entre migrantes e refugiados}

Em um mundo ideal, as pessoas poderiam confiar em seus governos para assegurar e proteger os seus direitos humanos básicos e a sua segurança física, contudo, principalmente no caso dos refugiados ambientais, seus países de origem são incapazes ou incapacitados de garantir tais direitos, uma vez que todo o país sofre com os problemas climáticos.

Inicialmente é necessário que se faça uma distinção entre migrante e refugiado, para um melhor desenvolvimento do estudo, visto que a migração e a proteção de refugiados são temas complementares, mas distintos. O Comitê Internacional da Cruz Vermelha (2020) adota uma ampla definição de migrantes, que "engloba todas as pessoas que deixaram suas casas em busca de segurança ou melhores perspectivas de vida no exterior, que podem estar sofrendo situação de estresse e precisem de proteção ou assistência humanitária”, cuja descrição compreende ainda os refugiados e requerentes de asilo. Os migrantes, segundo o Alto Comissariado das Nações Unidas para os Refugiados (Acnur), “optaram por viver no exterior, principalmente por motivações econômicas ou educacionais, podendo voltar com segurança ao seu país de origem assim que desejar” (ACNUR, 2020). Já os refugiados são tratados pelo Acnur como “pessoas que 
estão fora de seus países de origem por fundados temores de perseguição, conflito, violência ou outras circunstâncias que perturbam seriamente a ordem pública e que, como resultado necessitam de proteção internacional”, assim como disposto na Convenção Relativa ao Estatuto dos Refugiados de 1951 (ACNUR, 2016).

No Brasil, foi instituída em 2017 a Lei no 13.445, a qual dispõe em seu artigo $3^{\circ}$, já no inciso I, o princípio da universalidade, indivisibilidade e interdependência dos direitos humanos. Diante dos dispositivos, Pinhon e Brasil (2019, p. 79) trazem que:

O princípio da universalidade é fortemente ancorado no princípio da dignidade da pessoa humana e, igualmente, no princípio pro homine, portanto não admite a exclusão generalizada de estrangeiros não residentes da titularidade de direitos. Assim, todos os direitos fundamentados na dignidade da pessoa humana são extensivos aos estrangeiros, sejam os que residem ou não no território brasileiro. Afinal, a Lei $n^{\circ} 13.445$, de 2017, vai ao encontro do nosso pensamento, vez que a política migratória brasileira expõe que um dos princípios é a universalidade, bem como o artigo 122 da referida Lei exibe a necessidade de tratamento mais favorável ao migrante.

Em âmbito global, a Assembleia Geral da ONU, em 1948, elaborou a Declaração Universal dos Direitos do Homem, de modo a introduzir uma concepção contemporânea sobre os direitos humanos, revestida com características de universalidade e indivisibilidade (ROMERO, 2016, p. 264).

Portanto, como exposto pelos autores, tanto no ordenamento jurídico doméstico quanto no internacional, é notável a prevalência dos direitos humanos e, consequentemente, do princípio pro homine, que irriga todo o corpo normativo dos direitos humanos. Frisa-se ainda o forte vínculo do princípio da universalidade com o princípio da norma mais favorável ao ser humano. Os migrantes são protegidos pela lei internacional dos direitos humanos, ressaltando-se que a proteção é derivada de sua dignidade fundamental enquanto seres humanos.

\subsection{Mecanismos de proteção e integração das pessoas refugiadas}

A Convenção Relativa ao Estatuto dos Refugiados de 1951 foi o primeiro tratado internacional de grande importância acerca do instituto dos refugiados. Como tratado na seção anterior, de acordo com a Convenção, são consideradas refugiadas as pessoas que 
se encontram fora de seu país de origem em razão de fundado temor de perseguição, conflito, violência ou outras circunstâncias que perturbam seriamente a ordem pública e que necessitam de proteção internacional, uma vez que não seja viável o retorno aos seus locais de origem.

A Proteção Internacional dos Refugiados é o regime legal específico que protege os seus direitos. O Artigo 14 da Declaração Universal dos Direitos Humanos afirma o direito de toda e qualquer pessoa procurar e se beneficiar de refúgio, no entanto, nenhum conteúdo foi explicitado em relação à noção de refúgio em nível internacional até que a Convenção de 1951 Relativa ao Estatuto dos Refugiados foi adotada, e o Acnur foi incumbido de supervisar sua implementação. A Convenção da ONU de 1951 e seu Protocolo de 1967, assim como instrumentos legais regionais, são os pilares do regime de proteção de refugiados. Eles estabelecem uma definição universal e incorporam os direitos e deveres básicos dos refugiados. A disposição mais importante é o princípio de non-refoulement contido no Artigo 33, segundo o qual refugiados não podem ser expulsos ou devolvidos a situações onde suas vidas ou liberdade possam estar sob ameaça (PINHEIRO; TAVARES, 2016, p. 282). Os Estados são os primeiros responsáveis por assegurar essa proteção e o Acnur, a Agência da ONU para Refugiados, iniciada em 1950, trabalha estreitamente com governos, aconselhando-os e apoiando-os conforme suas necessidades a fim de implementar suas responsabilidades.

Segundo Liliana Lyra Jubilut, o Acnur foi estabelecido dentro do sistema das Nações Unidas, para efetivar, a nível universal, a proteção aos refugiados. "Foi instituído como um órgão subsidiário da ONU, em conformidade com o artigo 22 da Carta das Nações Unidas, capaz de atuar independentemente” (JUBILUT, 2007, p. 151).

A agência estreou com um mandato inicial de três anos, para reassentar refugiados europeus que estavam sem lar após a Segunda Guerra Mundial. Após sucessivas crises humanitárias nas décadas seguintes, percebeu-se a necessidade de ampliar o mandato da organização e expandir seu escopo de atuação, para não mais se limitar à Europa e às pessoas afetadas pela Segunda Guerra Mundial. Hoje, cerca de 63,9 milhões de pessoas estão sob seu mandato, entre elas solicitantes de asilo, refugiados e apátridas, se mantendo por meio de contribuições voluntárias de países, além de doações arrecadadas no setor privado e pessoas físicas.

De acordo com o artigo 35 da Convenção de 1951, são exigidos dos Estados Contratantes os comprometimento em cooperar com o Alto Comissariado das Nações Unidas para os Refugiados, ou qualquer outra instituição das Nações Unidas que lhe suceda. 
O Acnur não é uma organização supranacional e, portanto, não pode substituir a proteção dos países. Seu papel principal é garantir que os países estejam conscientes de suas obrigações, oferecendo proteção aos refugiados e a todas as pessoas que buscam refúgio. É atribuído à organização o encargo de assegurar que qualquer pessoa, em caso de necessidade, possa exercer o direito de buscar e obter refúgio em outro país e, caso deseje e seja possível, regressar ao seu país de origem.

\subsection{O reconhecimento dos refugiados ambientais pelo Direito Internacional}

Faz-se necessário acrescentar a distinção entre as expressões "refugiados ambientais" e "refugiados climáticos" - estes últimos incluem-se no primeiro grupo. Ou seja, embora as alterações climáticas contribuam para o aumento dos refugiados ambientais, existem ainda outros fatores que contribuem para as migrações de natureza ambiental (AMORIM, 2016, p. 242).

A migração de pessoas afetadas por problemas ambientais em busca de um lugar seguro para viver é uma crescente realidade, entretanto, não há amparo jurídico internacional específico sobre o tema e essas pessoas possuem apenas a proteção de organizações não governamentais e organizações internacionais. Reitera-se que o artigo primeiro do ato internacional aponta como requisito para a obtenção da condição de refugiado, um temor fundamentado de perseguição "por motivos de raça, religião, nacionalidade, grupo social ou opiniões políticas”(BRASIL, 1961), e não especificamente por adversidades ambientais.

Como versam Brasil; Costa (2018, p. 172):

o termo "refugiado ambiental" foi cunhado pela primeira vez em 1970 por Lester Brown (ACNUR), mas foi em 1985 que a expressão ficou altamente conhecida por meio da publicação de um paper do professor Essam El-Hinnawi, do Egyptian National Research Centre, no Cairo. Neste mesmo ano, o Programa das Nações Unidas para o Meio Ambiente (PNUMA) e o Alto Comissariado das Nações Unidas Para Refugiados (ACNUR) definiram os "refugiados ambientais como pessoas que foram obrigadas a abandonar temporária ou definitivamente a zona tradicional onde vivem, devido ao visível declínio do ambiente (por razões naturais ou humanas), perturbando a sua existência e/ou a qualidade da mesma de tal maneira que a subsistência dessas pessoas entra em perigo". 
De acordo com os autores, os refugiados ambientais, os quais também são designadamente conhecidos como refugiados climáticos, ecorefugiados e ecomigrantes, são forçados, nacional ou internacionalmente, temporária ou permanentemente, a se deslocarem por motivos ambientais. Os eventos que causam esse fenômeno podem ocorrer de forma inesperada, como exemplo dos maremotos, terremotos, tsunamis, vulcões, tufões ou lentamente como a desertificação, secas e processo erosivos do solo, que podem ocorrer por causas naturais ou pela interferência humana (BRASIL; COSTA, 2018, p. 172).

Segundo Carolina Claro (2018, p. 94), o “refugiado ambiental” é um refugiado não convencional, uma vez que não é protegido pela Convenção de 51, a qual no corpo do texto normativo estabelece que para os fins da Convenção são consideradas refugiadas as pessoas que possuem elementos característicos no contexto de uma condição específica determinada. Portanto, há de se reconhecer que os indivíduos que se deslocam para outros Estados com base em uma motivação estritamente ambiental não se enquadram na definição de refugiados prevista na Convenção Relativa ao Estatuto dos Refugiados de 1951.

Apesar da popularização do termo e de sua ampla discussão no meio acadêmico, ainda não é possível identificar um status juridicamente reconhecido para os migrantes ambientais. $O$ único tratado na história a adotar expressamente a noção de refugiados ambientais foi a Convenção Árabe para regular o status de Refugiados em Países Árabes, de 1994, que, em seu artigo $1^{\circ}$, considera como refugiados não apenas aqueles que correspondem à definição da Convenção de 1951, como também aqueles que, contra sua vontade, deixam seu país de origem em decorrência de desastres naturais. Contudo, tal convenção não foi ratificada por nenhum Estado, não tendo qualquer força vinculante. Desse modo, não há um instituto jurídico regional ou internacional que possibilite a classificação das migrações induzidas por causas naturais como motivo para a concessão da condição de refugiado.

Apesar do exposto, o termo refugiado ambiental é amplamente empregado atualmente como forma de chamar atenção para a situação de vulnerabilidade do grupo.

\section{Kiribati e as regiões do Pacífico afetadas pelo aquecimento global}

As mudanças climáticas, precipuamente o aquecimento global, vêm ocasionando mudanças humanas ao determinar o deslocamento dos habitantes dos locais que mais sofrem com citadas alterações, em busca de água ou alimento. A elevação do nível dos 
oceanos está condenando a existência de países como Kiribati, Tuvalu, Nauru, Vanuatu e Ilhas Maldivas, por exemplo. O temor do desaparecimento total desses países já levou milhões de pessoas a se deslocarem, migrando em busca de novos lares e da própria sobrevivência.

O Kiribati é um país com 115.847 habitantes, segundo dados do Banco Mundial (2018), e está localizado na região central do Oceano Pacífico, abrangendo uma área de aproximadamente 4 mil km² de extensão, dos quais apenas $811 \mathrm{~km}^{2}$ correspondem à superfície terrestre. Assim como em outros pequenos Estados insulares, o Kiribati já lida com fluxos de migrações dentro do seu território devido às mudanças climáticas. Conforme Paula Nunes, da Universidade Federal da Bahia, por conta da elevação do mar e da erosão do solo, o vilarejo de Tebunginako, localizado na ilha Abaiang, em Kiribati, foi evacuado em 2010 e os 400 habitantes remanejados para outras áreas. Quinze anos antes, Tebunginako havia passado por uma realocação parcial e construção de barreiras artificiais, no entanto não foi suficiente para conter as inundações e diminuição da área habitável (NUNES, 2016, p. 81).

Em 2011, o então presidente do Estado quiritibiano, Anote Tong, anunciou o programa "Migration with Dignity" com o intuito de viabilizar uma maneira mais segura de transferir os habitantes conforme seja necessário, objetivando auxiliar aqueles que desejam migrar antes que o território se torne inabitável, capacitando os habitantes de Kiribati com foco na migração laboral, considerando os acordos de cooperação entre alguns Estados insulares, Austrália e Nova Zelândia para o recebimento de um determinado número de migrantes no setor de agricultura e indústria (NUNES, 2016, p. 82). Em 2014, Tong anunciou a compra de parte do território das Ilhas Fiji, o estado de Natoavatu situado na Ilha Vanua Levu, para reassentar os migrantes ambientais quando o Estado de Kiribati for reduzido, uma vez que a comunidade internacional ainda não levantou alternativas efetivas para os casos de deslocamentos ambientais. Para tanto, foram investidos cerca de 9 milhões de dólares australianos em uma área de pouco mais de $20 \mathrm{~km}^{2}$, e ainda que o governo das Ilhas Fiji tenha declarado que irá receber a população de Kiribati quando for necessário, não existem precedentes, garantia legais ou formas de assegurar com que esse acordo verbal seja cumprido durante a gestão de governos futuros, pois a aquisição da área não implica, necessariamente, na soberania sobre esse território.

O Kiribati é o país de origem do primeiro indivíduo que apresentou um requerimento de refugiado ambiental ao Estado neozelandês, além da peculiaridade de ter adquirido parte do território das Ilhas Fiji para realizar a transferência de seus cidadãos. 


\subsection{Reconhecimento do caso loane Teitiota pela ONU}

Ioane Teitiota, habitante do Kiribati, se deslocou para a Nova Zelândia em busca de melhoria das condições de vida, por questões de conflitos de terra e falta de água potável. O território neozelandês mantinha uma categoria de vistos denominada "Pacific Acess Category”, voltado especialmente para alguns dos estados insulares que necessitam de apoio financeiro. Teitiota conseguiu essa permissão para exercer atividade laboral em 2007, o que lhe garantia a possibilidade de permanecer na Nova Zelândia por três anos, porém passado o período, em 2010, ele não obteve êxito na renovação de seu visto, e passou a residir ilegalmente com sua esposa e filhos na Nova Zelândia, recorrendo ao argumento de refúgio para continuar na localidade. De acordo com Paula Nunes, a defesa de Teitiota se baseou na alegação de que seu caso se tratava de questão humanitária que demandava ser resolvida no âmbito dos direitos humanos (NUNES, 2016, p. 85).

Após ter seu pedido de reconhecimento do status de refugiado climático negado pelas instâncias inferiores, o habitante do Kiribati apelou à Alta Corte da Nova Zelândia de Auckland. Dentre as questões alegadas pelo apelante, Pinheiro e Tavares (2016, p. 28) destacam que "os causadores do aumento do nível do mar e das mudanças climáticas são os gases do efeito estufa que são jogados na atmosfera por pessoas, de modo que a causa do deslocamento é, de forma indireta, uma atitude humana”.

Conseguinte, a Alta Corte da Nova Zelândia reconheceu que uma pessoa pode ser considerada como "refugiado ambiental" e ser benemérita de ajuda internacional. Entretanto, ainda que a expansão do nível do mar seja indiretamente causada pelo ser humano, essa alternativa não está enumerada na Convenção de 1951 e seu Protocolo Adicional de 1967, que são os únicos instrumentos universalmente vinculantes sobre o tema, de forma que o requerente não pode pleitear os mesmos direitos oferecidos aos refugiados nesses documentos (PINHEIRO; TAVARES, 2016, p. 28).

Nesse sentido, Saliba e Valle (2017, p. 10) trouxeram em síntese toda a jurisprudência neozelandesa: em 2013, o Tribunal de Proteção e Imigração da Nova Zelândia desconsiderou expressamente a interpretação da Corte Europeia de Direitos Humanos sobre o princípio do non-refoulement no caso do quiribatiano Ioane Teitiota, analisado o pedido de refúgio e concluindo que a degradação ambiental em seu país de origem não era base que o qualificasse para o status de refugiado. A corte avaliou os argumentos contra o retorno do peticionário em função da própria lei de imigração da Nova Zelândia, em vez de utilizar o direito internacional consuetudinário. Dessa forma, o 
Tribunal concluiu que, segundo a lei, o retorno não é proibido em todos os casos de perigo à vida do indivíduo, mas apenas em casos de privação arbitrária desta pelo próprio governo. Portanto, constatou-se que a situação de Teitiota não apresentava qualquer risco de que o governo do Kiribati o privasse arbitrariamente de sua vida, de modo que o retorno do indivíduo ao Kiribati não violaria qualquer obrigação internacional da Nova Zelândia. A decisão foi mantida em sede de apelação em 2014 e reafirmada pelo Tribunal no mesmo ano. Sua permanência na Nova Zelândia foi permitida tão somente com base em questões humanitárias excepcionais e no fato de que a família tinha fortes laços com a Nova Zelândia, não em uma obrigação internacional do Estado.

Ainda que o pedido tenha sido negado, devido à falta de instrumentos jurídicos internacionais sobre o tema, a análise feita pela Alta Corte da Nova Zelândia sobre o fenômeno das migrações causadas por fatores ambientais reforça os estudos e debates sobre o tema e alerta para a necessidade de uma atitude dos Estados. Em 2015, Ioane foi separado de sua família, expulso da Nova Zelândia e devolvido a Kiribati, apesar de argumentar que sua terra natal havia se tornado inabitável devido ao aumento do nível do mar e outros efeitos destrutivos da mudança climática, ele não foi considerado um refugiado devido o motivo de seu deslocamento, que teve origem em uma alteração ambiental. Em janeiro de 2020, o Comitê de Direitos Humanos da ONU reconheceu o refugiado por questões climáticas no caso Ioane Teitiota.

O caso do habitante de Kiribati e da Nova Zelândia é o principal exemplo da situação na qual se encontram os refugiados ambientais, marcados por legislações não definidas. Se, na prática, não se pode comparar a perseguição à degradação ambiental, por outro lado fica evidente que, embora haja o reconhecimento da problemática como questão de direitos humanos, a carência de posicionamento internacional sobre o assunto beneficia a "ação autônoma dos Estados sobre a responsabilidade de proteção do ser humano" (NUNES, 2016, p. 85).

No dia 24 de janeiro de 2020, a Agência da ONU para Refugiados comentou a decisão do Comitê de Direitos Humanos da ONU no aludido caso, no sentido de que, mesmo que o pedido de tutela por Teitiota tenha sido negado por não apresentar risco iminente, ficou determinado pelo Comitê que: "as pessoas que fogem dos efeitos das mudanças climáticas e desastres naturais não devem ser devolvidas ao seu país de origem caso, ao retornarem, seus direitos humanos básicos estiverem em risco" (ACNUR, 2020). Classifica-se a decisão como histórica, com implicações potencialmente abrangentes para a proteção internacional das pessoas deslocadas no contexto de mudanças 
climáticas e desastres naturais. Evidencia-se a importância da tomada de medidas preventivas pelos países ou mitigação dos danos associados às mudanças climáticas, que possam ocasionar a futura migração forçada, implicando em obrigações internacionais a serem cumpridas.

\section{Considerações finais}

O estudo, partindo da perspectiva de constantes modificações, apontou as diversas transformações que ocorreram no meio ambiente, sobretudo em relação ao clima, em decorrência do aquecimento global gerado pela industrialização. Como consequência, as pessoas que habitam os locais mais afetados pelas alterações climáticas, precisaram se deslocar, demandando direitos mínimos à própria sobrevivência e de suas famílias, resultando no surgimento de uma nova categoria de migrantes: os refugiados ambientais.

É de suma importância que o ordenamento jurídico de cada país trilhe caminho simultâneo ao Direito Internacional, sem ceder quanto a valores e princípios, que são, por vezes, encobertos quando se observa somente o direito interno.

Constatou-se a necessidade de uma resposta internacional adequada e o reconhecimento do status jurídico próprio para a nova categoria dos refugiados ambientais, além da construção de estratégias de prevenção e combate das múltiplas causas que forçam os deslocamentos. Embora discussões acerca da proteção acordada a migrantes ambientais sejam recorrentes, muito pouco tem sido alcançado na prática. Destaca-se como proposta a urgência no tratamento específico da matéria no sentido de buscar reconhecimento e proteção jurídica dos migrantes ambientais em face da aplicação do princípio internacional pro homine.

Nota-se, assim, um quadro de incerteza jurídica envolvendo os migrantes ambientais, estando sua proteção sujeita à discricionariedade dos Estados receptores. Quanto ao caso específico de Kiribati, percebe-se que o problema ambiental é fator decisivo na opção pelo deslocamento, pois, além da população ter a qualidade de vida reduzida, a previsão de desaparecimento do território em virtude do aumento do nível do mar é alarmante. A demanda de Ioane Teitiota na Alta Corte da Nova Zelândia chamou a atenção do mundo para o problema. No entanto, o papel da corte é adequar o caso às normas vigentes.

Embora a reivindicação de proteção por Teitiota tenha sido negada, o Comitê de Direitos Humanos da ONU determinou que as pessoas que fogem dos efeitos das 
mudanças climáticas e desastres naturais não devem ser devolvidas aos seus países de origem, caso, ao retornarem, seus direitos humanos básicos estejam em risco. Tal determinação tem implicações potencialmente abrangentes para a proteção internacional das pessoas deslocadas no contexto de mudanças climáticas e desastres naturais.

Para suprir a lacuna normativa existente propõe-se uma abordagem integrada, identificando elementos importantes nos regimes internacionais que possam contribuir para construção de um compromisso global inovador e compatível com a recente dinâmica internacional, além de se destacar a importância de os países tomarem medidas preventivas contra os danos associados às mudanças climáticas.

Evidencia-se a necessidade de buscar a segurança jurídica por meio das normas internacionais já existentes e a inevitabilidade da constante adaptação e consequente transformação da lei diante de casos concretos e cenários que fomentam tais demandas, além de enfatizar a urgência do posicionamento da comunidade internacional, preferencialmente de forma vinculante, evitando a exposição de indivíduos vulneráveis à violações de seus direitos devido aos fatores ambientais, uma vez que os instrumentos vigentes pertinentes ao refúgio não abarcam a categoria referida de forma direta.

\section{REFERÊNCIAS}

ACNUR. Convenção das Nações Unidas sobre o Estatuto dos Refugiados. Disponível em: http://www. acnur.org/t3/fileadmin/Documentos/portugues/BDL/Convencao_relativa_ao_Estatuto_dos_Refugiados.pdf. Acesso em: 10 jun. 2020.

ACNUR. Decisão do Comitê de Direitos Humanos da ONU sobre mudança climática dá sinal de alerta, diz ACNUR. 2020. Disponível em: http://www.acnur.org/portugues/2020/01/24/decisao-do-comite-de-direitos-humanos-da-onu-sobre-mudanca-climatica-da-sinal-de-alerta-diz-acnur/.Acesso em: 18 jun. 2020.

ACNUR. Protegendo Refugiados no Brasil e no Mundo. 2020. Disponível em: http://www.acnur.org/ portugues/wp-content/uploads/2020/03/Cartilha-Institucional-Final_site.pdf. Acesso em: 3 jul. 2020.

ACNUR. Refugiados” e “Migrantes: perguntas frequentes. 2016. Disponível em: http://www.acnur.org/portugues/2016/03/22/refugiados-e-migrantes-perguntas-frequentes/\#:-:text=Refugiados\%20s\%C3\%A3o\%20pessoas\%20que\%20est\%C3\%A3o,necessitam\%20de\%20\%E2\%80\%9Cprote\%C3\%A7\%C3\%A3o\%20internacional\%E2\%80\%9D. Acesso em: 15 jun. 2020.

AMORIM, T. S. S. Os refugiados ambientais e a grave e generalizada violação de direitos humanos: análise do artigo $1^{\circ}$, inciso III, da lei n ${ }^{\circ} .9 .474 / 97$. Refúgios e Migrações: práticas e narrativas. Florianópolis: NEFIPO/UFSC, 2016. Disponível em: http://www.nefipo.ufsc.br/files/2012/11/refugios-migracoes.pdf. Acesso em: 15 maio 2020. 
BANCOMUNDIAL. 2018. Relatório Anual de 2018 do Banco Mundial. Washington, DC: Banco Mundial. Disponível em: http://openknowledge.worldbank.org/bitstream/handle/10986/30326/211296PT. pdf. Acesso em: 25 jun. 2020.

BAND. Refugiados climáticos: 143 milhões serão forçados a migrar. Band Jornalismo. 30 de jan. de 2020. 1min19s.Disponívelem:http://www.youtube.com/watch?v=vOeQM=-0y7Rw\&list=WL\&index118=\&t0s. Acesso em: 25 jun. 2020.

BECK, U. Sociedade de risco: rumo a uma outra modernidade. São Paulo: Editora 34, 2010. 384 p.

BRASIL, D. R.; COSTA, F. V. Desigualdade ambiental: mudanças climáticas e fluxo migratório. Atualidade na ciência jurídica: intercâmbio ibero-americano. Instituto Politécnico da Maia; Iberojur. 2018. Disponível em: http://www.academia.edu/37895040/DESIGUALDADE_AMBIENTAL_ MUDAN\%C3\%87AS_CLIM\%C3\%81TICAS_E_FLUXO_MIGRAT\%C3\%93RIO Acesso em: 30 jun. 2020.

BRASIL. Decreto n. 50.215, de 28 de janeiro de 1961. Promulga a Convenção relativa ao Estatuto dos Refugiados, concluída em Genebra, em 28 de julho de 1951. Diário Oficial da União, 30 jan. 1961.

BRASIL. Decreto n. 2.652, de $1^{\circ}$ de julho de 1998. Promulga a Convenção-Quadro das Nações Unidas sobre Mudança do Clima, assinada em Nova York, em 9 de maio de 1992. Disponível em: http://www. planalto.gov.br/ccivil_03/decreto/D2652.htm. Acesso em: 17 jul. 2020.

BRASIL. Lei n. 13.445, de 24 de maio de 2017. Institui a Lei de Migração. Disponível em: http://www. planalto.gov.br/ccivil_03/_ato2015-2018/2017/lei/113445.htm\#:-:text=Art.,pol\%C3\%ADticas\%20 p\%C3\%BAblicas\%20para\%20o\%20emigrante. Acesso em: 15 jun. 2020.

BBC News. O país superpovoado que poderá ficar inabitável em 15 anos. 2020. Disponível em: http:// www.bbc.com/portuguese/internacional-51197329. Acesso em: 30 jun. 2020.

CLARO, C. de A. B. O aporte jurídico do direito dos refugiados e a proteção internacional dos refugiados ambientais. In:RAMOS, A. de C.; RODRIGUES, G.; ALMEIDA, G. A. de (org.). 60 Anos de ACNUR: perspectivas de futuro. São Paulo: CL-A, 2011.p. 241-269.

CLARO, C. de A. B. O Conceito de "Refugiado Ambiental”. In: JUBILUT, L. L.; ALLGAYER, A. (org.). Refugiados Ambientais. Boa Vista: Editora da UFRR, 2018.

COMITÊ INTERNACIONAL DA CRUZVERMELHA (CICV). Migrantes, refugiados e requerentes de asilo. 2020. Disponível em: http://www.icrc.org/pt/acoes/migrantes Acesso em: 16 jun. 2020.

DE SÁ, A. B. S.; VERBICARO, L. P. Vida nua, refugiados ambientais e a desmistificação do cidadão universal. In: BRASIL, D. R.: RIBEIRO, L. G. G.; FREITAS, S. H. Z. (org.) Temas e problemas de direitos humanos. 1. ed. Maringá, 2018. Disponível em: http://www.uit.br/mestrado/images/publicacoes/E_ BOOK_Temas_e_problemas_de_direitos_humanos_23.pdf. Acesso em: 30 jun. 2020.

DERANI, C. Refugiado ambiental. Disponível em: http://escola.mpu.mp.br/dicionario/tiki-index. php?page=Refugiado+Ambiental. Acesso em: 20 jun. 2020.

JUBILUT, L. L. O direito internacional dos refugiados e sua aplicação no orçamento jurídico brasileiro. São Paulo: Método, 2007. 
NOSCHANG, P. G.; BICA, J. F. Mudanças climáticas e consequências humanas: os migrantes ambientais. In: MOURA, A. B. de; DAL RI, L. (org.) Imigração e cidadania: uma releitura de institutos jurídicos clássicos a partir do modelo Europeu. Itajaí, SC: Ed. da Univali, Florianópolis, SC: Ed. da UFSC, 2018. Disponível em: http://www.univali.br/ppcj/ebook. Acesso em: 16 jun. 2020.

NUNES, P.P.M. Invisiveis e irreconhecíveis: entre a proteção dos deslocados ambientais e a soberania estatal. Dissertação apresentada ao Programa de Mestrado em Relações Internacionais da Universidade Federal da Bahia. 2016. Disponível em: http://repositorio.ufba.br/ri/bitstream/ri/21431/1/Disserta\%C3\%A7\%C3\%A30\%20Completa\%20-\%20Paula\%20Pimenta\%20Matoso\%20Nunes.pdf. Acesso em: 16 jun. 2020.

ONU. ACNUR elogia decisão do Comitê de Direitos Humanos da ONU sobre mudança climática. Disponível em: http://nacoesunidas.org/acnur-elogia-decisao-do-comite-de-direitos-humanos-da-onu-sobre-mudanca-climatica/. Acesso em: 18 jun. 2020.

ONU. Qual a diferença entre 'refugiados' e 'migrantes'? 2017. Disponível em: http://nacoesunidas. org/qual-a-diferenca-entre-refugiados-migrantes/. Acesso em 16 jun. 2020.

ONU. A ONU e a mudança climática. 2020. Disponível em: http://nacoesunidas.org/acao/mudanca-climatica/. Acesso em: 16 jun. 2020.

ONU. Mudanças climáticas são ‘ameaça existencial’ para a humanidade. 2018. Disponível em: http:// nacoesunidas.org/mudancas-climaticas-sao-ameaca-existencial-para-a-humanidade-diz-onu/.Acesso em: $1^{\circ}$ jul. 2020.

PEREIRA, L. D. D. Uma visão brasileira do conceito refugiado ambiental. In: RAMOS, A. de C.; RODRIGUES, G.; ALMEIDA, G. A. de (org.). 60 Anos de ACNU R: perspectivas de futuro. São Paulo: CL-A Ed, 2011.p. 221-240.

PINHEIRO, G. M.; TAVARES, M. de A. O recente caso do pedido de "refúgio climático" na Nova Zelândia e seu contexto internacional. Refúgios e Migrações: práticas e narrativas. Florianópolis: NEFIPO/ UFSC, 2016. p. 279. Disponível em: http://www.nefipo.ufsc.br/files/2012/11/refugios-migracoes. pdf. Acesso em: 15 maio 2020.

PINHON, L.; BRASIL, D. Lei de migração: um compromisso com a prevalência dos direitos humanos? Revista Direito e Justiça: reflexões sociojurídicas, v. 20, n. 36.p 71-96. Santo Ângelo, 2019. Disponível em: http://www.researchgate.net/publication/338193909_LEI_DE_MIGRACAO_UM_COMPROMISSO_COM_A_PREVALENCIA_DOS_DIREITOS_HUMANOS. Acesso em: 30 jun. 2020.

RAMOS, É. P. Refugiados ambientais: em busca de reconhecimento pelo direito internacional. Tese de Doutorado. Faculdade de Direito - USP - São Paulo. 2011. Disponível em: http://www.acnur.org/ fileadmin/Documentos/portugues/eventos/Refugiados_Ambientais.pdf Acesso em: $1^{\mathrm{o}}$ jul. 2020.

REZEK, J. F. Direito internacional público: curso elementar. 13. ed. rev. São Paulo: Saraiva, 2011.

ROMAN, M. T. Humanizing climate change. TEDxXavierUniversity, 2018. Disponível em: http://www. youtube.com/watch?v=hoOkFDIHsD4 Acesso em: $1^{\circ}$ jul. 2020.

ROMERO, T. G. Fluxos migratórios e as novas categorias de refugiados: os refugiados ambientais e os refugiados econômicos. Refúgios e Migrações: práticas e narrativas. Florianópolis: NEFIPO/UFSC, 2016. Disponível em: http://www.nefipo.ufsc.br/files/2012/11/refugios-migracoes.pdf Acesso em: 15 maio 2020. 
SALIBA, A. T.; VALLE, M. F. V. do. A proteção internacional dos migrantes ambientais. Revista de Informação Legislativa: RIL, v. 54, n. 213, p. 13-37, jan./mar. 2017. Disponível em: http://www12.senado. leg.br/ril/edicoes/54/213/ril_v54_n213_p13. Acesso em: 19 jun. 2020.

SALIBA, C. A.; RIBEIRO, J. C. J. As mudanças climáticas e a conservação das florestas: desertificação e refugiados climáticos. Direito ambiental e socioambientalismo I. XXVIII Encontro Nacional do Conpedi Goiânia. Anais [...] Florianópolis: CONPEDI, 2019. Disponível em: http://conpedi.danilolr. info/publicacoes/no85g2cd/9hdn9m49/bp81jkk85X4HN279.pdf. Acesso em: 29 jun. 2020.

UNITED NATIONS High Commissioner for Refugees (UNHCR). Climate change and disaster replacement. Disponível em: http://www.unhcr.org/climate-change-and-disasters.html. Acesso em: $1^{0}$ jul. 2020. 